\title{
ANALISIS KRITERIA PERSONAL BRANDING SELEBGRAM NON SELEBRITI (STUDI DESKRIPTIF KUALITATIF AKUN INSTAGRAM@LIPPIELUST)
}

\author{
Dita Rachmawati, Dini Salmiyah Fithrah Ali, \\ Prodi S1 Ilmu Komunikasi, Fakultas Komunikasi dan Bisnis, Universitas Telkom \\ faladita@yahoo.co.id ${ }^{l}$
}

\begin{abstract}
Social media nowadays has become tool of marketing and promotion of goods, services, and personal like Instagram. Being a celebgram should have a strong Personal Branding, has uniqueness, the difference from other celebgram in order to have a long existence to be celebgram on social media Instagram. Rissa is a non-celebrity celebgram. Rissa's known as an endorser for beauty project this leap how to work together on a project professional with many brands in the country and abroad. Rissa became a celebgram with a very specific focus that is more beauty that leads to lipstick. This study analyze about how Personal Branding criteria non celebrity celebgram. The method used is descriptive qualitative with indicator 11 Authentic Personal Branding criterion according to Rampersad. In this study, Rissa's Personal Branding has a personality as which is character, values, vision that suits personal ambition, moral code and behavior, consistent, focused on one field, acknowledged and experienced, unique, connected to the audience, owns good relationship with partnerwork and always make self improvement in Instagram account@ @ippielust.
\end{abstract}

Keywords - Personal Branding, Social Media, Instagram, Celebgram, Rissa Stellar

\begin{abstract}
ABSTRAK
Media sosial saat ini telah menjadi sarana dalam melakukan pemasaran maupun promosi baik barang, jasa, maupun personal khususnya salah satunya adalah Instagram. Untuk menjadi seorang selebgram dibutuhkan Personal Branding yang kuat, memiliki kekhasan, perbedaan dari selebgram lainnnya agar mempunyai eksistensi yang bertahan lama dalam menjadi seorang selebgram pada media sosial Instagram. Rissa merupakan seorang selebgram yang bukan dari kalangan selebriti, yang disebut selebgram non selebriti. Personal Branding yang dilakukan Rissa menjadikannya endorser dan berhasil bekerja sama secara project professional dengan banyak brand dalam negeri maupun luar negeri. Rissa menjadi selebgram dengan fokus yang sangat spesifik yaitu beauty yang lebih mengarah kepada lipstick. Penelitian ini menganalisis tentang bagaimana kriteria Personal Branding selebgram non selebriti. Sedangkan untuk metode yang digunakan ialah deskriptif kualitatif dengan indikator 11 kriteria Authentic Personal Branding menurut Rampersad. Dalam penelitian ini menghasilkan bahwa Personal Branding yang dilakukan Rissa memiliki kepribadian yang memiliki karakter, nilai-nilai, visi yang sesuai dengan ambisi pribadi, kode moral dan perilaku, konsisten, berfokus pada satu bidang, diakui dan berpengalaman, unik, terhubung dengan khalayak, memiliki hubungan yang baik dengan partner pekerjaan dan selalu melakukan perbaikan diri dalam akun Instagram@lippielust.
\end{abstract}

Kata Kunci: Personal Branding, Media Sosial, Instagram, Selebgram, Rissa Stellar 


\section{PENDAHULUAN}

Tren yang sedang berkembang sekarang ini ialah dimana dalam platform Instagram sebuah perusahaan/penjual dapat menjual/ mempromosikan produknya lewat profil mereka sendiri atau melalui orang lain. Dimana perusahaan/penjual bisa mempromosikan produknya lewat profil pengguna dengan followers yang banyak yang dapat meluaskan cakupan produknya dengan orang yang terpercaya pada dunia maya tersebut. Biasanya penjual/perusahaan meminta promosi kepada orang yang memiliki Personal Branding yang sesuai dengan klasifikasi yang diinginkan penjual/perusahaan. Branding tidak hanya untuk perusahan, tetapi sekarang ada tren baru yang biasa disebut dengan Personal Branding. Dalam Personal Branding, seseorang membentuk branding tersendiri untuk akun sosial medianya. Untuk menegaskan citra mereka di dalam akun sosial media tersebut.

\section{Montoya (2002) Personal Branding} proses strategi tentang sengaja mengendalikan bagaimana orang lain memandang diri dan mengelola persepsi tersebut secara strategis untuk membantu untuk mencapai tujuan yang telah direncanakan sebelumnya.

Dalam dunia maya saat ini daritahun ke tahun mengalami peningkatan dimana tanda bahwa masyarakat Indonesia suka berselancar di dunia maya. Misalnya Instagram yang berada di urutan ketiga penggunaan terbanyak di Indonesia. Sekarang pada sosial media Instagram terdapat sebuah tren yang dimana disebut selebgram. Selebgram diidentifikasi sebagai artisnya dunia maya Instagram yang merupakan berasal dari non celebrity. Tetapi mereka terkenal di platform tersebut. Selebgram telah menjadi tren yang dimana mereka bisa popular setara dengan selebriti dengan hanya menggunakan platform Instagram. Sekarang ini para selebgram terdiri dari bermacam-macam, misalnya tentang kecantikan, pecinta makanan, komedian, pecinta travelling dan lain- lain yang saling memamerkan konten mereka masing masing pada profilnya. Untuk membedakan dari yang lainnya dan agar terlihat lebih menonjol, selebgram harus memiliki perbedaan tersendiri agar lebih dikenal oleh orang lain maupun sebagai alat untuk mendapatkan profit dari konten media sosial Instagram. Untuk membentuk Personal Branding, para selebgram sebelumnya pasti akan membentuk feeds mereka agar lebih menarik dilihat oleh pengguna lainnya pada platform tersebut. Karena untuk menjadi selebgram, Personal Branding adalah hal yang sangat penting. Rissa Stellar memiliki hal yang unik. Dalam akun Instagramnya yang bernama

$$
\text { @lippielust Rissa membranding }
$$
dirinya sebagai selebgram beauty influencer khususnya pada bagian bibirnya. Rissa sendiri merupakan selebgram non selebriti. Rissa dikenal sebagai selebgram beauty influencer yang biasanya memposting tentang dirinya sebagai content creator dan lipstickswatcher.

Selain itu, Rissa dijuluki sebagai the queen of lipstick swatches, yang buktikan dengan banyaknya brand yang sudah bekerja sama. Beberapa post Instagram @ lippielust ada yang di- regram langsung oleh 
brand internasional seperti Stila, Girlactic, dan Tarte. Selain dari brand internasional, Rissa banyak di endorse dan didaulat untuk men-swatch lipstick untuk brand ternama tanah air, salah satunya seperti Make Over Cosmetics. Rissa juga berkolaborasi dengan brand evt meluncurkan produk lip remedies by@lippielust.

Media sosial Instagram sebagai wadah pengekspresian diri dengan cara Personal Branding. Termasuk Rissa yang menjadikan Instagram sebagai wadah untuk pengekspresian dirinya di dunia maya dengan cara mengunggah konten-konten tertentu pada akun Instagramnya. Terlihat dari kontenkonten yang diunggah Rissa di Instagram lebih cenderung tentang makeup yang ditampilkan.

Rissa Stellar merupakan selebgram yang bukan berasal dari selebritas dengan spesifikasi beauty yang lebih mengarah kepada lipstick di dan merupakan Indonesia's ultimate source for swatches and reviews. Selain itu, Rissa berhasil menggaet berbagai brand ternama baik luar maupun dalam negeri. Jika dilihat sekilas, kebanyakan dari kita kurang begitu mengetahui jika selebgram non selebriti tersebut berhasil melakukan kerja sama dengan banyak brand dengan hanya melakukan Personal Branding dalam akun Instagramnya. Maka dari itu peneliti ingin mengetahui unsur apa saja yang menjadikan Rissa dipilih oleh para brand tersebut. Berdasarkanuraian dari latar belakang diatas, penulis tertarik untuk menganalisis bagaimana kriteria Personal Branding selebgram non selebriti melalui akun media sosial Instagram @1ippielust yang dilakukan oleh Rissa Stellar?

\section{METODE}

Metode dalam penelitian ini adalah kualitatif karena penelitian ini berisi data yang berbentuk kata-kata bukan angka- angka. Data kualitatif diperoleh dengan wawancara, observasi, dokumentasi dan kajian literatur. Penelitian kualitatif tidak menggunakan populasi, dikarenakan penelitian ini berangkat dari kasus tertentu yang ada pada situasi sosial yang tertentu juga dan hasil dari kajiannya tidak akan diberlakukan pada populasi, tetapi ditransferkan ke tempat lain pada situasi sosial pada kasus yang dipelajari. Sampel dalam penelitian kualitatif tidak disebut responden, melainkan narasumber, partisipan atau informan. (Sugiyono, 2011:216).

Subjek penelitian yang diteliti oleh penulis adalah Rissa Stellar pemilik akun Instagram @lippielust. Sedangkan untuk objek penellitian yang ditelitinya adalah analisis kriteria Personal Branding dari akunInstagram @lippielust.

Penulis melakukan pengumpulan data dengan melakukan wawancara dengan informan yang bersangkutan. Gorden dalam Herdiansyah (2009:118) menyebutkan bahwa wawancara adalah percakapan antara dua orang dimana seseorang mencoba mengarahkan pembicaraan untuk mendapatkan informasi untuk beberapa tujuan tertentu. Teknik wawancara yang digunakan oleh penulis adalah wawancara semi terstruktur. Menurut Bungin (2007:115) observasi adalah metode yang digunakan dalam sebuah penelitian dengan bantuan penginderaan melalui pengamatan. Dalam 
penelitian ini, penulis menggunakanobservasi tidak terstruktur dimana penulis harus

mampu mengembangkan pengamatannya terhadap suatu objek. Menurut Herdiansyah (dalam Herdiansyah 2010) menyatakan bahwa dokumentasi merupakan salah satu cara agar subjek mendapatkan sebuah sudut pandang dari subjek melalui medium tertulis atau lainnya yang langsung dibuat oleh subjek itu sendiri. Dokumentasi ditambahkan dalam penelitian ini dari informan yang sudah dipilih agar analisis penulis lebih lengkap. Tinjauan literatur ditambahkan penulis untuk menunjang penelitian. Penulis membaca jurnal, buku dan media yang terkait agar penelitian yang sedang diteliti ini mendapatkan analisis yang relevan.

Data yang sudah didapat dalam penelitian ini akan dianalisis secara induktif dan dilaksanakan selama penulis melakukan penelitian di lapangan. Nasution dan Moleong (1991) dalam Suharsaputra (2012:216-221) menyebutkan bahwa analisis data yang akan dilakukan meliputi mereduksi data, menyajikan data, display data, menarik kesimpulan dan melaksanakan verifikasi.

\section{HASIL DAN PEMBAHASAN}

Disesuaikan dengan tujuan penelitian yaitu mengetahui kriteria Personal Branding yang dilakukan oleh akun Instagram @ lippielust dan menganalisanya. Dimana kriteria Personal Branding yang dipakai oleh penulis adalah 11 kriteria Authentic Personal Branding menurut Rampersad.
TABEL 1. HASIL WAWANCARA

\begin{tabular}{|c|c|c|}
\hline No & Variabel & $\begin{array}{c}\text { Hasil Wawancara Rissa Stellar (@ } \\
\text { lippielust) }\end{array}$ \\
\hline 1. & Keotentikan & $\begin{array}{l}\text { Selebgram yang memiliki visi, nilai- } \\
\text { nilai dan karakter yang sesuai } \\
\text { dengan ambisi pribadi sebagai } \\
\text { selebgram yang berfokus pada } \\
\text { beauty yang lebih spesifik yaitu } \\
\text { lipstick. }\end{array}$ \\
\hline 2. & Integritas & $\begin{array}{l}\text { Memiliki tata perilaku yang baik } \\
\text { dengan khalayaknya. }\end{array}$ \\
\hline 3. & Konsisten & $\begin{array}{l}\text { Konsisten dengan bidangnya dan } \\
\text { dilakukan dengan terus-menerus. }\end{array}$ \\
\hline 4. & Spesialisasi & $\begin{array}{l}\text { Memiliki spesialisasi yang fokus } \\
\text { dengan satu bidang yaitu beauty } \\
\text { yang lebih kepada lipstick. }\end{array}$ \\
\hline 5. & Wibawa & $\begin{array}{l}\text { Pengalaman selebgram diakui oleh } \\
\text { akun Instagram brand yang telah } \\
\text { bekerja sama dimana mengunggah } \\
\text { foto @lippielust. }\end{array}$ \\
\hline 6. & Keberbedaan & $\begin{array}{l}\text { Memiliki hal yang berbeda dari } \\
\text { selebgram kompetitor lainnya yaitu } \\
\text { fokus pada satu bidang dengan } \\
\text { konten yang lebih berkonsep. }\end{array}$ \\
\hline
\end{tabular}




\begin{tabular}{|c|c|c|}
\hline 7. & Relevan & $\begin{array}{l}\text { Target audience telah sesuai } \\
\text { dengan apa yang diinginkan oleh } \\
\text { selebgram. }\end{array}$ \\
\hline \multirow[t]{2}{*}{8.} & Visibilitas & $\begin{array}{l}\text { Memiliki jadwal dalam konten yang } \\
\text { diunggah. }\end{array}$ \\
\hline & & $\begin{array}{l}\text { Namun pernah tidak melakukannya } \\
\text { secara terus menerus. }\end{array}$ \\
\hline 9. & Kegigihan & $\begin{array}{l}\text { Rissa terus menciptakan konten } \\
\text { dengan konsep-konsep yang baru. }\end{array}$ \\
\hline 10. & Kebaikan & $\begin{array}{l}\text { Rissa berhasil menjalin hubungan } \\
\text { baik Dengan para brand yang sudah } \\
\text { pernah bekerja sama dengannya. }\end{array}$ \\
\hline 11. & Kinerja & $\begin{array}{l}\text { Mengembangkan pengolahan kon- } \\
\text { ten untuk eksistensinya dan menjalin } \\
\text { hubungan yang baik. }\end{array}$ \\
\hline
\end{tabular}

\section{A. Keotentikan (Authencity)}

Dalam Personal Branding menurut Rampersad (2008:19) keotentikan adalah menjadi diri sendiri yang dibangun dengan visi, nilai-nilai, karakter milik sendiri yang diselaraskan dengan ambisi pribadi. Individu harus memaparkan keotentikan dirinya yang sebenarnya yang dimulai dengan menentukan ambisi dari pribadi itu sendiri.

Berdasarkan kriteria keotentikan oleh Rampersad (2008:19), peneliti menyimpulkan bahwa Personal Branding yang dilakukan Rissa dalam akun Instagram @lippielust dalam hal visi, nilai-nilai, karakter yang dimiliki sendiri, selaras dengan ambisi pribadi yang ditampilkan.

\section{B. Integritas (Integrity)}

Selain keotentikan, dalam melakukan Personal Branding harus memperhatikan kriteria-kriteria lainnya, yang selanjutnya itu adalah integritas. Menurut Rampersad (2008:19) integritas adalah tentang kode moral yang merupakan penerapan perilaku pelaku terhadap khalayaknya.
Peneliti mengambil kesimpulan berdasarkan kriteria Personal Branding integritas menurut Rampersad (2008:19) bahwa Rissa dalam akun Instagram @1ippielust telah melakukan kode moral yang merupakan penerapan perilaku pelaku terhadap khalayaknya.

\section{Konsisten (Consistency)}

Konsisten merupakan hal yang diperlukan dalam melakukan Personal Branding, kekonsistenan menurut Rampersad (2008:19) memerlukan keberanian, konsistensi dapat berupa pesan yang disampaikan secara terus menerus oleh pelaku Personal Branding dalam mengunggah sebuah konten yang sama di media sosial. Selain itu, dapat berupa perilaku yang disampaikan secara terus menerus dan tetap pada jati dirinya sendiri.

Hal yang dilakukan Rissa dapat dikatakan konsisten, karena Rissa secara terus menerus menyampaikan pesan dimana perilakunya yang memang tidak berubah hanya pada satu fokus saja dalam akun Instagramnya dalam melakukan Personal Branding.

\section{Spesialisasi (Specialization)}

Menurut Rampersad (2008:19) spesialisasi itu hanya berfokus dalam satu bidang bakat atau keterampilan. Dalam melakukan Personal Branding spesialisasi itu perlu untuk menjadikan kita terfokus dengan bidang yang dijalani.

Rissa bisa dikatakan terspesialisasi karena kontennya dalam melakukan Personal Branding dalam akun Instagramnya hanya 
berfokus pada satu bidang saja yaitu beauty yang lebih spesifik lagi ialah lipstick.

\section{E. Wibawa (Authority)}

Wibawa atau otoritas dapat menurut Rampersad (2008:19) diakui dalam bidang tertentu dimana diakui sebagai orang yang memang berpengalaman di bidangnya dalam melakukan Personal Branding.

Sesuai dengan Rampersad (2008:19), dengan pemaparan diatas, bahwa Rissa diakui sebagai orang yang ahli dalam bidang tersebut dan merupakan orang yang berpengalaman dalam bidangnya.

\section{F. Keberbedaan (Differentiation)}

Berbeda berdasarkan merek dan mempunyai keunikan dalam melakukan Personal Branding merupakan salah satu kriteria Personal Branding dalam poin keberbedaan menurut Rampersad (2008:19).

Bahwa Rissa memiliki keunikan tersendiri yang membedakan dirinya dengan orang lain yaitu memilih konten swatched lipstick dan membuatnya menjadi lebih berkonsep sesuai dengan ciri brand yang bekerja sama dengannya.

\section{G. Relevan (Relevant)}

Personal Branding dapat dianggap relevan jika terhubung dengan khalayak yang dianggap penting menurut Rampersad (2008:19). Terhubung dengan khalayak memiliki artian mempunyai keselarasan antara target khalayak dengan pelaku Personal Branding.
Melalui kriteria relevan menurut Rampersad (2008:19), peneliti dapat menyimpulkan bahwa Rissa dengan sukses menjalankan Personal Branding dalam poin relevan dimana target khalayak dengan konten yang diunggah sudah selaras.

\section{H. Visibilitas (Visibility)}

Personal Branding yang disiarkan berkali-kali, terus menerus, secara konsisten dan dilakukan berulang kali merupakan Visibilitas menurut kriteria Personal Branding Rampersad (2008:19). Dimana konten harus berkali-kali dilakukan, terus menerus diunggah secara berulang kali.

Peneliti menarik kesimpulan bahwa Rissa kurang dalam kriteria Personal Branding visibilitas melalui akun media sosial Instagram, dimana Rissa pernah tidak terus menerus melakukan unggahan pada akun Instagramnya sehingga terpaan followers Rissa tidak selalu langsung naik.

\section{Kegigihan (Persistance)}

Konsisten pada Personal Branding yang dibentuk, tidak merubah haluan, setia, tidak menyerah, yakin terhadap diri sendiri dan tetap berfokus terhadap satu bidang merupakan kriteria Personal Branding dalam poin kegigihan menurut Rampersad (2008:20). Brand yang dibentuk harus berkembang secara organik dan memerlukan waktu untuk tumbuh.

Melalui kriteria kegigihan menurut Rampersad (2008:20), Rissa berhasil konsisten pada Personal Branding yang dibentuk, tidak merubah haluan, setia, tidak 
menyerah, yakin terhadap diri sendiri dan tetap berfokus terhadap satu bidang yang dipilih.

\section{J. Kebaikan (Goodwill)}

Hubungan baik yang berkaitan dengan hal yang positif dan bermanfaat sehingga akan memberikan hasil baik yang lebih tahan lama merupakan penjelasan dari kriteria poin kebaikan menurut Rampersad (2008:20).

Rissa telah sukses menjalin hubungan dengan baik yang berkaitan dengan hal yang positif dan bermanfaat sehingga memberikan hasil baik yang lebih tahan lama.

\section{K. Kinerja (Performance)}

Menurut Rampersad (2008:20) kinerja merupakan poin paling penting setelah brand pelaku Personal Branding itu sendiri dikenal. Jika tidak melakukan perbaikan diri akan menjadi sesuatu yang palsu.

Rissa melakukan kinerja dengan baik dengan mempunyai kinerja yang terukur dan selalu melakukan perkembangan pada kontennya dalam akun Instagram @lippiekust.

\section{KESIMPULAN}

Rissa hadir dengan akun Instagram @ lippielust dengan sebelas kriteria Personal Branding keotentikan, integritas, konsisten, spesialisasi, wibawa, keberbedaan, relevan, visibilitas, kegigihan, kebaikan dan kinerja. Keotentikan, sebagai selebgram yang memiliki ambisi pribadi yang selaras dengan karakter dan merupakan pelopor swatcher lipstick di Indonesia. Integritas memiliki tata perilaku yang baik terhadap khalayaknya. Konsisten, terus menerus dalam menyampaikan pesan dan perilakunya yang memang tidak berubah hanya pada satu fokus saja. Spesialisasi, konten dalam melakukan Personal Branding dalam akun Instagramnya hanya berfokus pada satu bidang saja yaitu beauty yang lebih spesifik lagi ialah lipstick. Wibawa, bahwa Rissa diakui sebagai orang yang ahli dalam bidang beauty yang lebih spesifik yaitu lipstick dan merupakan orang yang berpengalaman dalam bidangnya sehingga banyak brand yang mengunggah kembali hasil kerjasamanya dengan Rissa. Keberbedaan, Rissa memiliki keunikan tersendiri yang membedakan dirinya dengan orang lain yaitu memilih konten swatched lipstick dan membuatnya menjadi lebih berkonsep sesuai dengan ciri brand yang bekerja sama dengannya. Relevan, target khalayak yang diinginkan dengan konten yang diunggah sudah selaras. Visibilitas, memiliki jadwal dalamunggahan konten, namun pernah tidak terus menerus melakukan unggahan pada akun Instagramnya. Kegigihan, tidak merubah haluan, setia, tidak menyerah, yakin terhadap diri sendiri dan tetap berfokus terhadap satu bidang yang dipilih yaitu beauty. Kebaikan, dimana Rissa sukses menjalin hubungan dengan baik dengan banyak brand. Kinerja, dilakukannya dengan baik yang dibarengi oleh kinerja yang terukur dan selalu melakukan perkembangan pada kontennya dalam akun Instagram @lippiekust. Namun, Rissa pernah tidak mengunggah secara terusmenerus dan berkali-kali kontennya dalam akun Instagramnya saat Rissa merasa jenuh dimana kurang sesuai pada sisi visibilitas. 


\section{DAFTAR PUSTAKA}

Bungin, Burhan. 2007. Penelitian Kualitatif: Komunikasi, Ekonomi, Kebijakan Publik, Dan Ilmu Sosial Lainnya. Jakarta: Prenada Media Group.

Herdiansyah, Harris. 2010. Metode Penelitian Kualitatif Untuk Ilmu-Ilmu Sosial. Jakarta: Salemba Humanika.

Montoya, Peter. 2002. The Personal Branding Phenomenon. Nashville: Vaughan Printing.

Poerwandari, E.K. 2007. Pendekatan

Kualitatif Untuk Penelitian Perilaku Manusia. Jakarta: Lpsp3 Fakultas Psikologi Universitas Indonesia.

Rampersad. Hubert K. 2008. Authentic Personal Branding. Jakarta: Ppm Publishing.

Sugiyono. 2011. Metode Penelitian Kuantitatif Kualitatif Dan R\&D. Bandung: Alfabeta.

Suharsaputra, Uhar. 2012. METODE PENELITIAN Kuantitatif, Kualitatif, dan Tindakan. Bandung: PT Refika Aditama. 